RTDF2008-74033

\title{
DEVELOPMENT AND FABRICATION OF STATE-OF-THE-ART END STRUCTURES FOR BUDD M1 CARS
}

\author{
Richard Stringfellow \\ TIAX LLC \\ Cambridge, Massachusetts, USA
}

\author{
Christopher Paetsch \\ TIAX LLC \\ Cambridge, Massachusetts, USA
}

\author{
Gabriel Amar \\ Taylor Raynauld Amar \& Associates \\ Montreal, Quebec, Canada
}

\section{ABSTRACT}

The Volpe Center and the Federal Railroad Administration are engaged in active research aimed at improving rail vehicle crashworthiness. One component of this research is focused on improving the performance of passenger train cab cars during collisions with heavy objects at grade crossings. New standards have been approved by the American Public Transportation Association that increase the strength requirements for cab car end structures and impose further requirements on their ability to absorb energy during a collision. The FRA has issued a notice of proposed rulemaking (NPRM) to include these new standards in 49CFR238.211. These standards include requirements for demonstration of energy absorption through either quasi-static or dynamic tests. The intent of each test method is to demonstrate a minimum level of energy absorption-120,000 $\mathrm{ft}-\mathrm{lbs}$ for a corner post load and 135,000 ft-lbs for a collision post load-while limiting occupied volume intrusion to less than 10 inches.

To aid in the development of these new standards, the FRA and Volpe Center are conducting a set of three tests: quasi-static loading of both the collision and corner posts, and dynamic loading of the collision post only. (A dynamic test of the corner post was conducted as part of an earlier program). These tests were developed to illustrate testing methodologies and to demonstrate the feasibility of the new energy absorption and large deformation requirements. In+ each test, the post is loaded 30 inches above the underframe by a proxy object that is 36-inches wide, with a 48-inch diameter cylindrical face.

In support of this testing program, the research reported here focused on the design and fabrication of end frames suitable for retrofitting onto the cab end of a Budd M1 cab car.
The design of an end frame for retrofit onto the cab end of a Budd Pioneer cab car was modified to account for differences between the two car designs. In addition, reinforcements to the M1 car body and connections from the end frame to the car body were designed and fabricated.

An FEA model of the end frame retrofit onto the M1 cab car was developed based upon the detailed design. A series of linear and nonlinear static, quasi-static, and dynamic FEAs were performed to evaluate the performance of the design. Preliminary analyses revealed the need for a few minor modifications to the connections in order to meet design requirements; these were incorporated into the final design for manufacture.

Components for the end frame, connections between the end frame and the car body, and reinforcements to the car body were fabricated based on detailed design drawings and then assembled and connected to the reinforced M1 Car, from which the original end frame had been cut off.

A successful dynamic test was completed in April, 2008; quasi-static tests are scheduled for summer 2008. The results of FEA model predictions are compared with the results of the dynamic test.

\section{INTRODUCTION}

In an effort to increase the safety of passenger train occupants, the Federal Rail Administration (FRA) is proposing amendments to regulations governing the structural behavior of the front end of cab cars and multiple-unit locomotives [1]. In addition to numerous requirements for the strength of key end frame components, the proposed regulations impose requirements for energy absorption and maximum intrusion distance, following recommendations of the American Public Transportation Association (APTA) [2]. 
The proposed rule provides two alternative test methods for demonstrating absorption of collision energy. Following the quasi-static method, the front end structure must demonstrate compliance under the following two loading scenarios:

- Collision post loading-135,000 ft-lbs energy absorption;

- Corner post loading-120,000 ft-lbs energy absorption.

In each case, the post is loaded 30 inches above the underframe and must not deflect permanently by more than 10 inches longitudinally. Following the dynamic method, the structure must be capable of withstanding the longitudinal impact of a 10,000 lb proxy object, traveling at the following speeds:

- Collision post impact-21 mph;

- Corner post impact-20 mph.

The proxy object has a cylindrical shape, with a diameter of 48 inches and a width of 36 inches. The object is oriented with its axis perpendicular to the direction of impact, and is positioned 30 inches above the underframe. Intrusion into the occupied volume is limited to 10 inches.

The total kinetic energy of the impacting object is approximately $147,000 \mathrm{ft}-\mathrm{lb}$ for the collision post impact and $134,000 \mathrm{ft}-\mathrm{lb}$ for the corner post impact. These levels of energy are about $10 \%$ higher than the corresponding energy levels specified for the quasi-static tests, reflecting recognition that some of the kinetic energy of the collision will not be transferred into deformation of the end structure of the car.

The work summarized in this paper is part of a broader research program conducted by the Volpe Center in support of the FRA that is aimed at evaluating the behavior of cab car end structures and, in particular, assessing the effective equivalence of the two alternative test methods.

In an earlier program sponsored by the Volpe Center and the FRA [3], a design was developed for a cab car end frame that satisfies Federal regulations that were introduced in 1999. This so-called 'State-of-the-Art' (SOA) end frame was fabricated and retrofit onto Budd Pioneer cab cars for testing.

A dynamic coil impact test of the corner post of the SOA end frame was conducted at the FRA's Transportation Technology Center (TTC) in June 2002. The results of the test indicated that the SOA end frame was a substantial improvement to a design built to pre-1999 federal regulations (1990's design) [4]. The corner post of the SOA end frame deflected about 9 inches due to impact of a 40,000 lb, 6-ft diameter by 4 -ft wide steel coil traveling at $14 \mathrm{mph}$, with the post fracturing in a few locations, but remaining attached to the end frame. In contrast, in the corresponding test of the 1990's design, the impact of the coil caused the corner post to completely separate from the end frame, displacing the full extent of the operator cab volume.

To help evaluate the proposed rules and test methods described above, the Volpe Center is conducting three additional tests of the SOA end frame. A dynamic test of a coil impacting the collision post was conducted in April 2008, and is described in [5]. Two quasi-static tests are scheduled for the summer of 2008 that will load the end frame under the collision post and corner post loading scenarios, respectively.

Budd Pioneer cars were not available for use in this testing program; instead, Budd M1 cars were utilized. The objective of the program described here was to adapt the SOA end frame design originally built for retrofit onto the Budd Pioneer car so that it could be retrofit onto a Budd M1 car.

\section{END FRAME DESIGN}

Several differences between the Pioneer car and the M1 car, both geometrical and structural, were addressed in developing the design. The car body profiles are different, with the M1 car having a more rounded section. There are also significant differences in floor height that must be accounted for. For the most part, the design of the adaptation of the SOA end frame to the M1 car can be categorized as having four components:

- $\quad$ Preparation of the M1 car;

- $\quad$ Reinforcement of the structure on the M1 car so that it can withstand the higher loads associated with the SOA end frame requirements for multiple tests

- $\quad$ Addition of connections between the post-cut M1 car and the SOA end frame;

- Modification of the end frame to account for geometrical and structural differences between the Pioneer and M1 cars.

\section{Preparing the M1 Car for Retrofit}

The end of the existing M1 car was cut off at appropriate locations to accommodate the required connections to the SOA end frame. A single planar cut was made around most of the side and roof structure of the car body. A more complex three-dimensional cut was made around the forward end of the draft sill. Figure 1 show a CAD representation of the cut M1 car and Figure 2 shows a photograph of the actual cut M1 car prior to retrofit. 


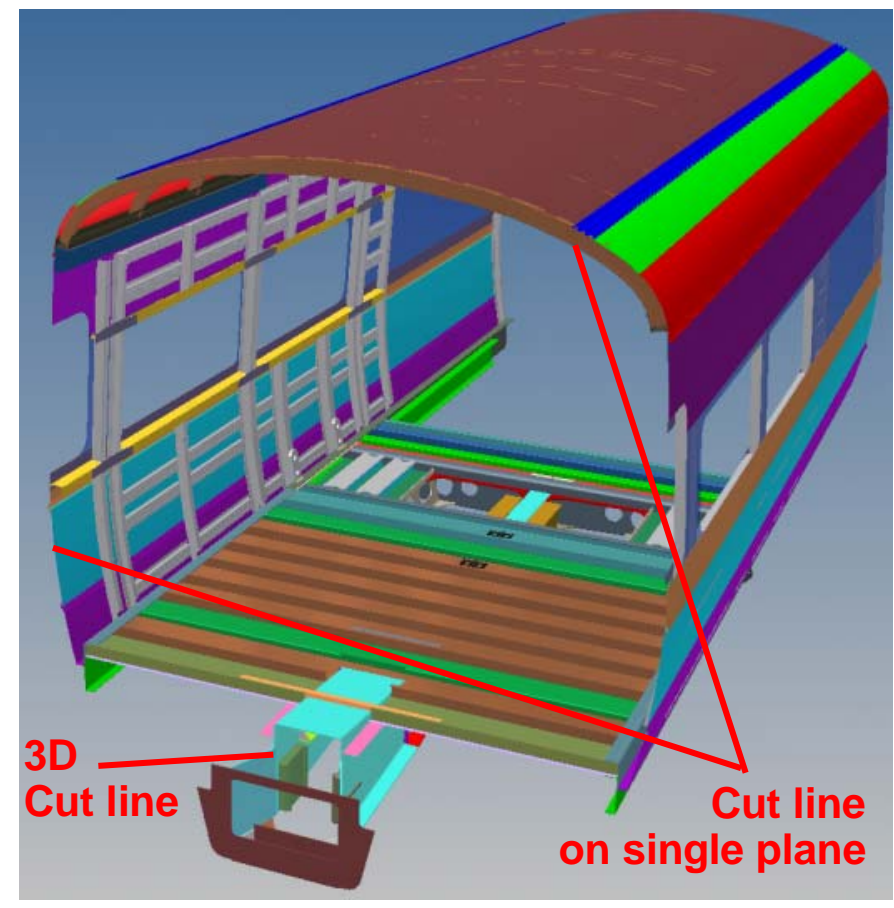

Figure 1. CAD representation of the car cut line

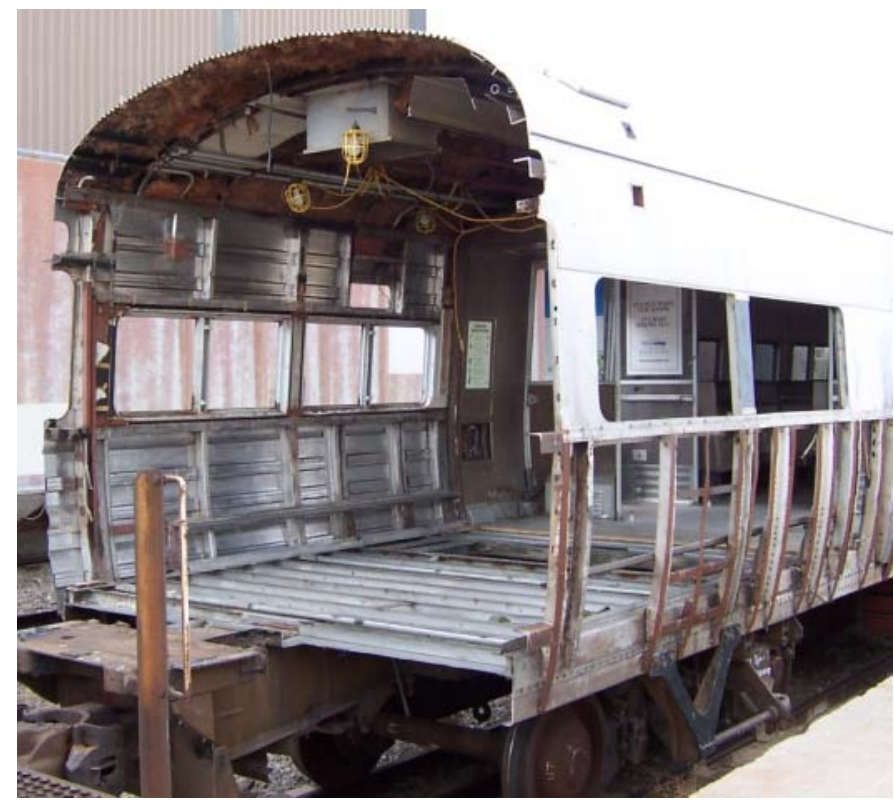

Figure 2. The cut M1 car ready for retrofit

\section{Car Reinforcement}

Reinforcements were added to the M1 car body to ensure minimal damage to the existing car during each test. The sideframe posts were shortened and 0.188-inch doubling plates were mechanically fastened to the bottom of the roof rail and on the side directly below the existing rail, as shown in Figure 3. The doubling plates were used to provide mechanical fastening to the original stainless steel sideframe. In addition, a 0.25 -inch thick tube was welded directly below the existing roof rail to provide an interface with the connections to the end frame, and was attached to the posts with brackets to restore torsional fixity of the top of the original posts, as shown in Figure 4.

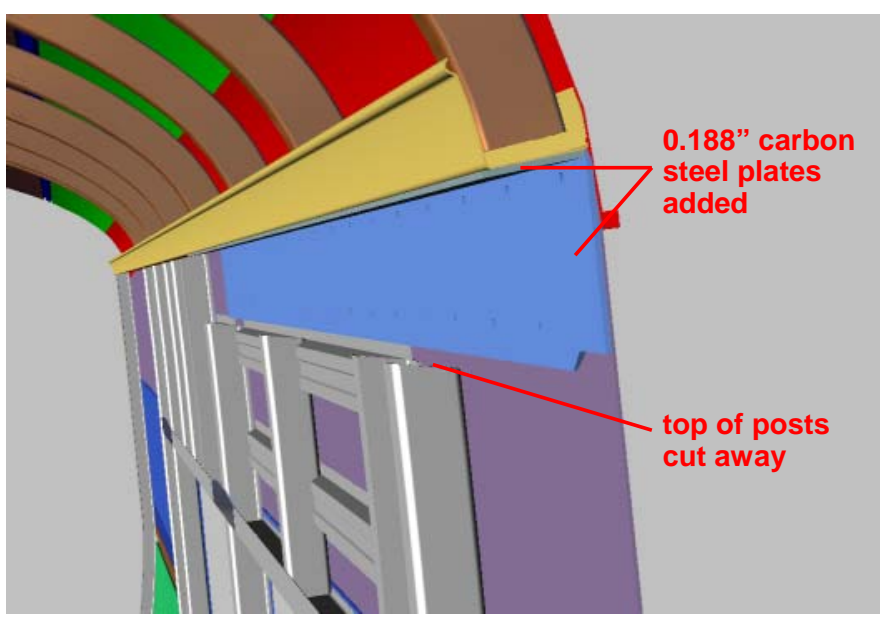

Figure 3. Reinforcement plates fastened to side wall and roof rail

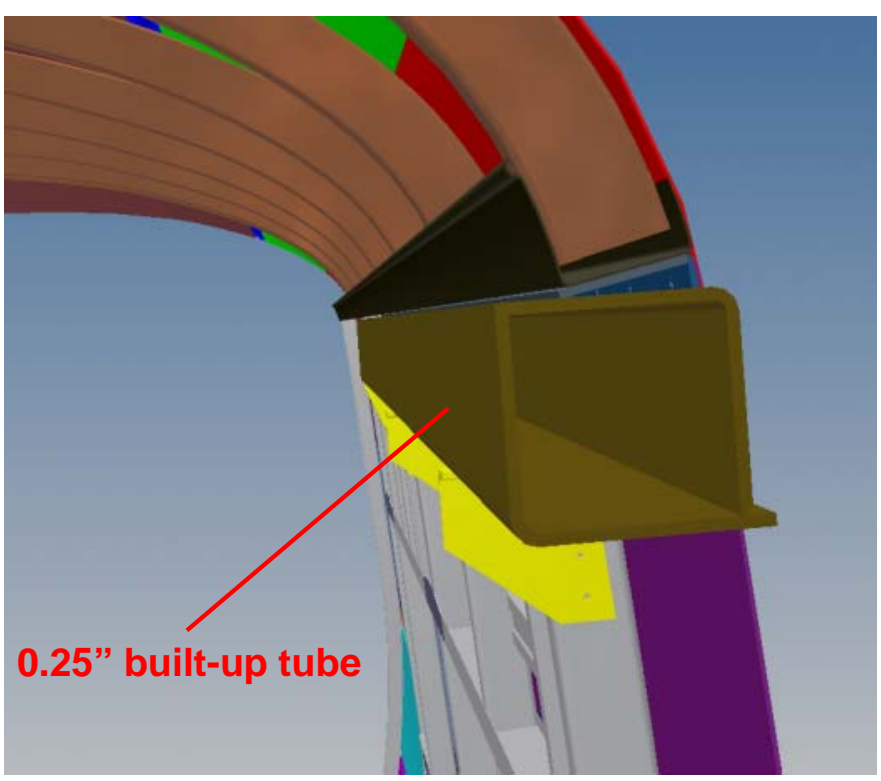

Figure 4. Built-up tube welded to doublers for longitudinal load path into roof rail

Reinforcement plates, 0.188 inches thick, were mechanically fastened to the side sill to form a box structure. Above the floor pans, an open channel was mechanically fastened to the top of the side sill. These modifications are shown in Figure 5. 


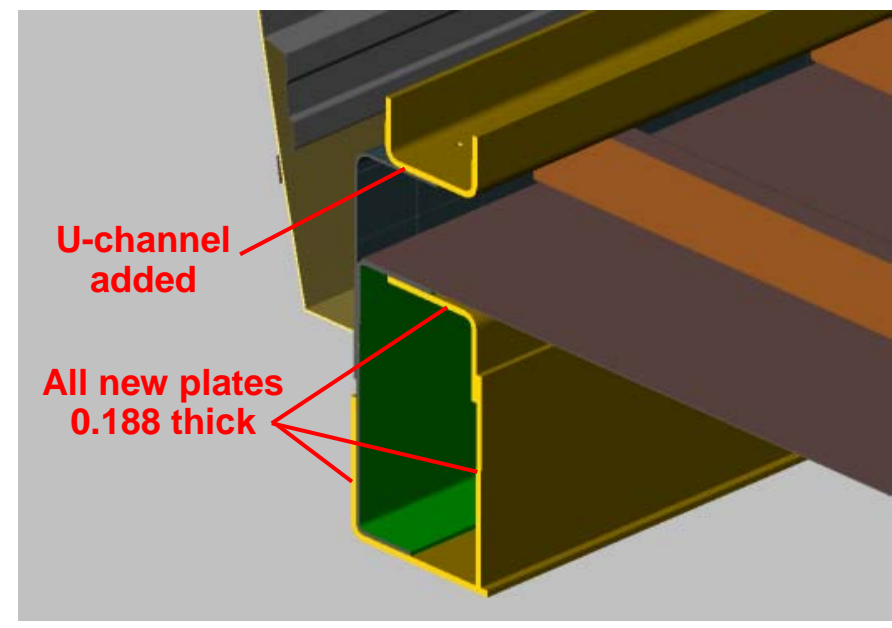

Figure 5. Side sill reinforcements for M1 car

A triangular bracing structure, shown in Figure 6, was added to fulfill part of the structural function of the side and end sheets that were removed. The brace adds racking stability to the end of the car and vertical restraint to the center sill without affecting its crush strength.

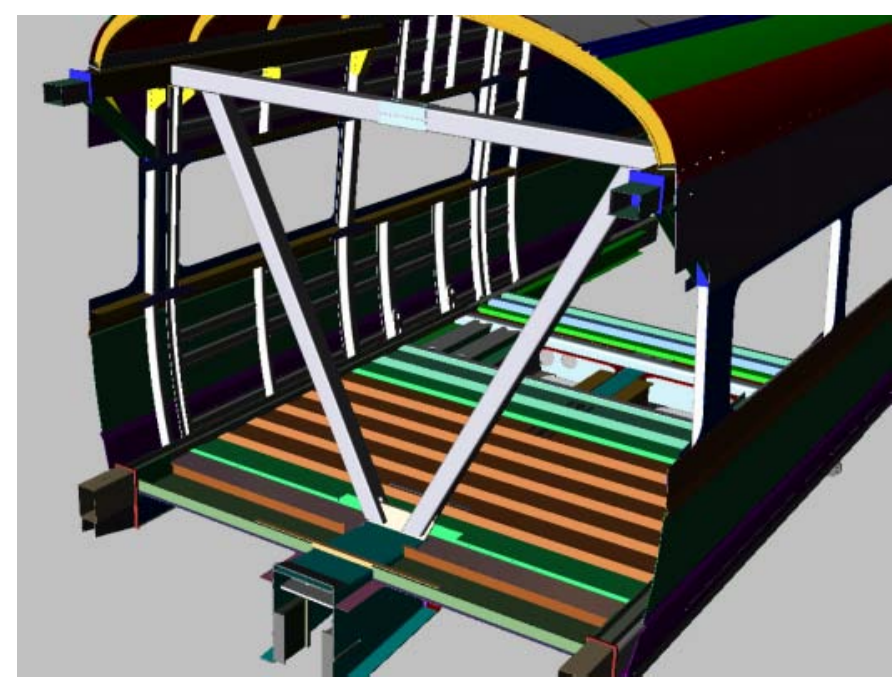

Figure 6. Triangular bracing structure

\section{Connections to the End Frame}

There are five connection points between the car body and the end frame - one at the center sill, two at the side sills and two at the roof rails. Each of these connections was redesigned for the retrofit.

The connection of the roof rail to the end frame includes a 0.179-inch thick tube with a rectangular cross section tapering along its inside edge, as shown in Figure 7. The tube is capped on either end with half inch thick plates to distribute the bearing load over the anti-telescoping (AT) beam and roof rail tube, respectively.

At the side sill, the connection includes two 0.134-inch thick C-channels forming a rectangular tube on top, and two 0.188-inch thick tapered plates providing the transition in height from the bottom of the side sill to the bottom of the end beam, as illustrated in Figure 8. The tube is closed at both ends with half inch plates to distribute the bearing loads.

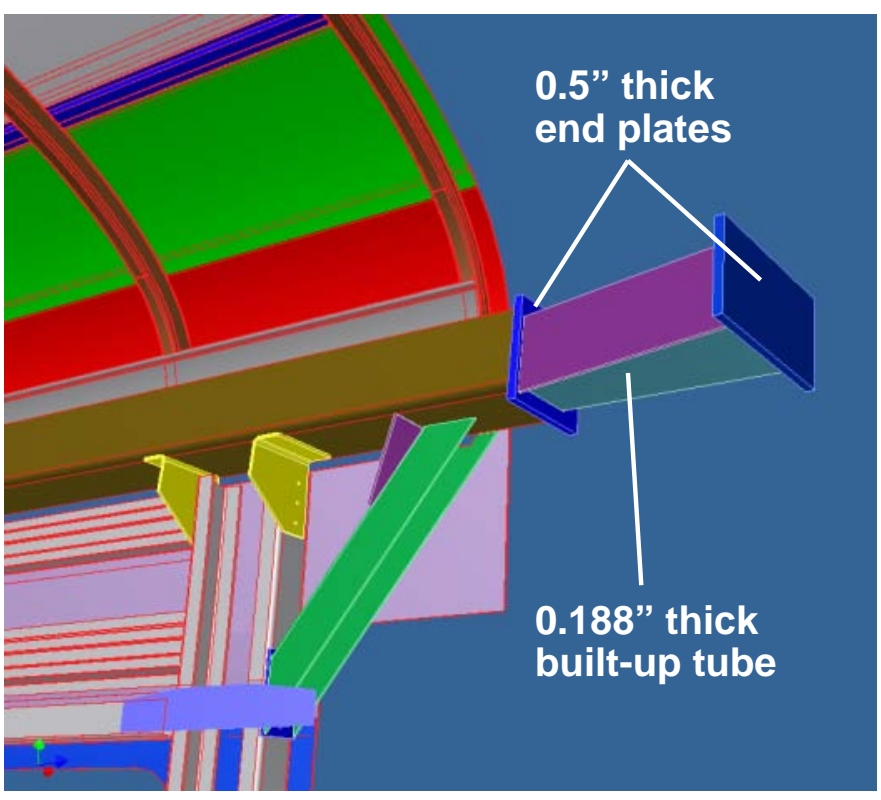

Figure 7. Roof rail connections

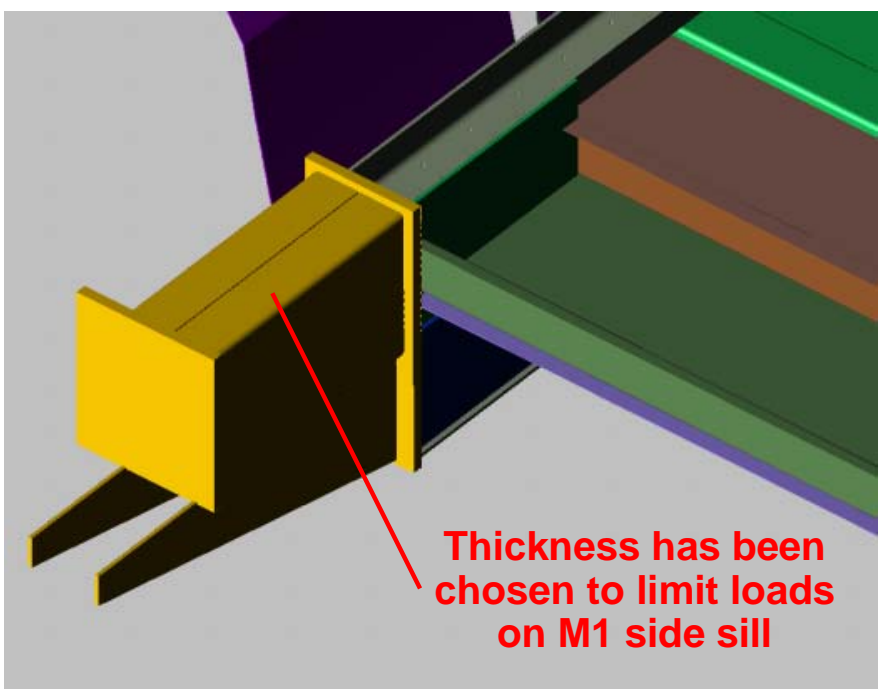

Figure 8. Side sill connections

The connection at the center sill is similar to the SOA design for a Pioneer car. However, because there is a height difference between the Pioneer and M1 cars, components were added above and below the top flange of the center sill, as shown in Figure 9. In addition, the bell mouth was extended to accommodate the deeper SOA end beam. 


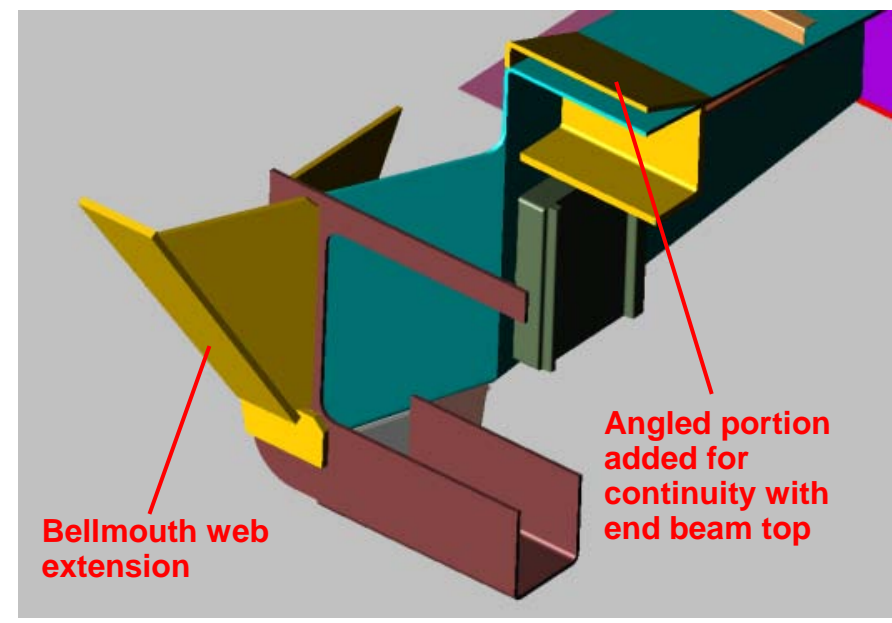

Figure 9. Cross sectional view of the center sill with transitional structure for M1 car

\section{Modifications to the End Frame}

The design of the SOA end frame itself required only a few modifications to adapt to the M1 car body. Due to the rounded nature of the $\mathrm{M} 1$ car body as compared to the Pioneer cab body, the lateral extent of the AT beam was changed slightly so that it extends beyond the corner post by 1.5 inches, as compared to 1.0 inches for the Pioneer Car. Figure 10 shows the SOA end frame with the bulkhead plate and the AT beam and buffer beam cover plates removed so that the reinforcing gusset plates can be viewed. The complete car model is shown in Figure 11.

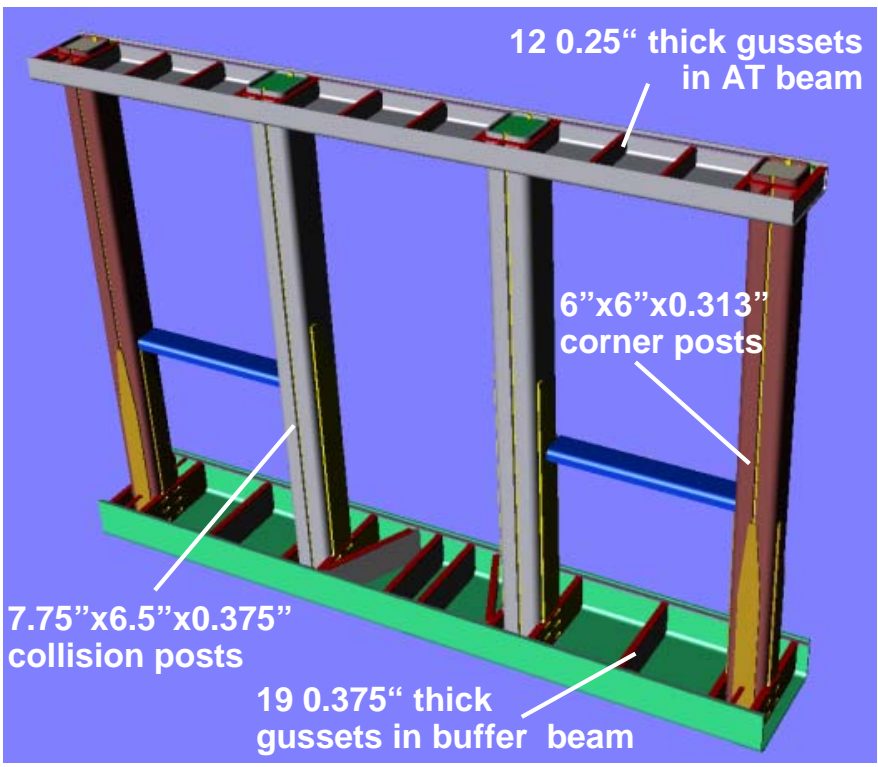

Figure 10. The end frame with the bulkhead, AT beam and buffer beam cover plates removed

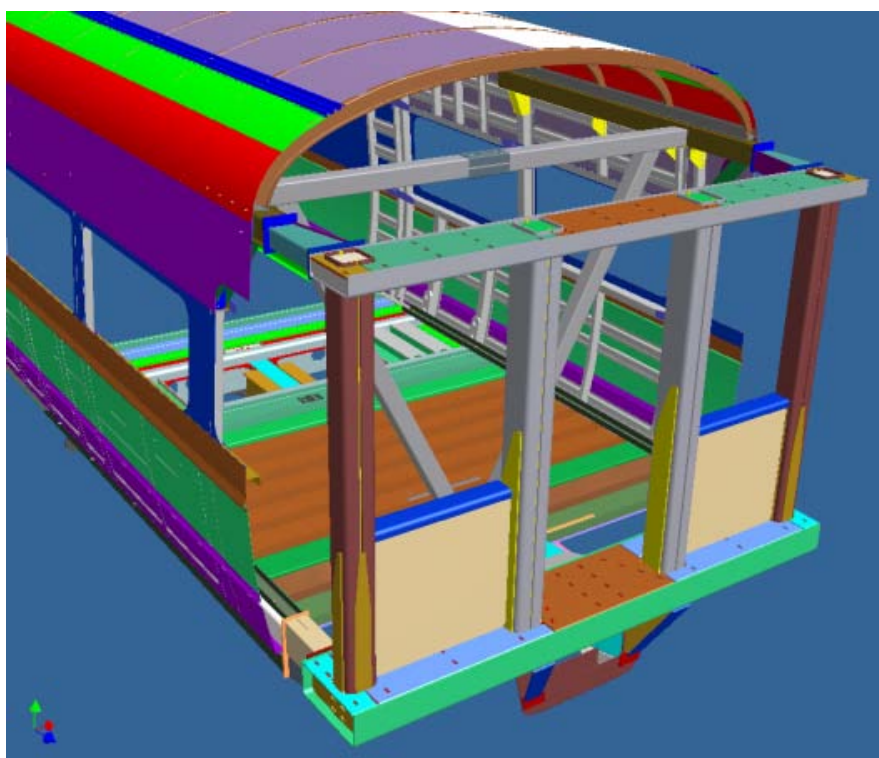

Figure 11. The complete CAD model for the M1 car with SOA end frame

\section{FABRICATION AND ASSEMBLY}

The many components that make-up the SOA end frame, plus the connections and reinforcements of the car body, were fabricated based on detailed drawings. A single set of reinforcement parts was fabricated with the intention of reusing them for all of the tests. Three complete sets of connection and end frame parts were made, one for each of the tests. All together a total of approximately 670 parts were fabricated. The parts were fabricated from a selection of carbon steels, each with a minimum specified strength of 50 ksi.

The end frame was assembled and then attached to the cut M1 car. A photograph of the assembled end frame installed on the M1 Car prior to the dynamic coil impact test is shown in Figure 12.

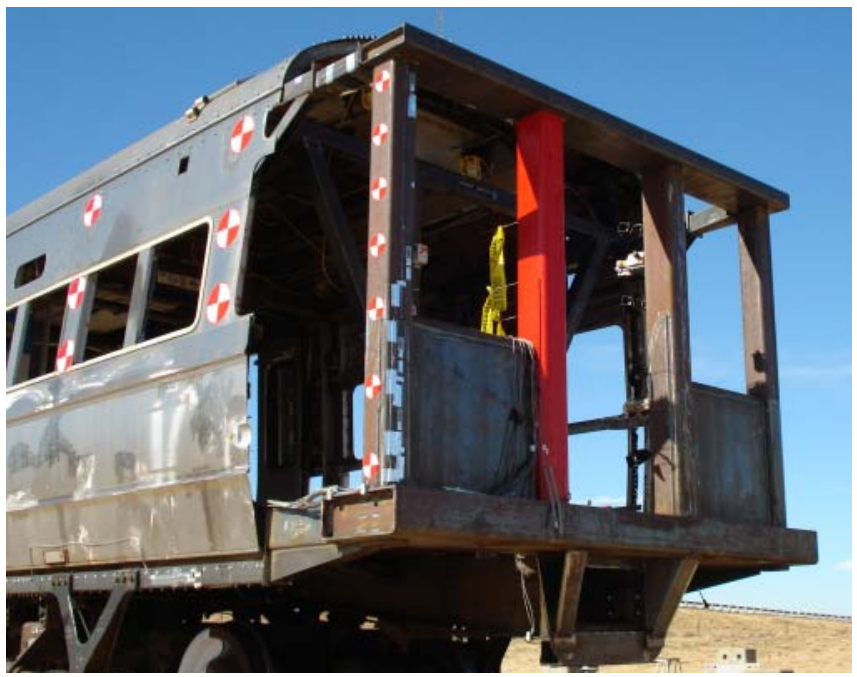

Figure 12. SOA end frame integrated with M1 car 
The SOA end frame was originally designed to be made from A710 grade A, class 3 steel. Unfortunately, A710 steel is in extremely high demand and could not be procured in a timely manner. For this reason, the steel used to construct the end frames was modified, with A572-50 and A656-80 selected as substitutes. Material test reports for the procured steel lots were used as the basis for the properties input into the FEA models. A comparison between the mechanical properties of A710 and the replacement steels is shown in Table 1.

Table 1. Comparison of steel mechanical properties

\begin{tabular}{|l|l|l|l|l|}
\hline $\begin{array}{c}\text { Plate } \\
\text { Thickness (in) }\end{array}$ & Material & $\begin{array}{c}\text { Yield } \\
\text { Strength (ksi) }\end{array}$ & $\begin{array}{c}\text { Ultimate } \\
\text { Strength (ksi) }\end{array}$ & $\begin{array}{c}\text { Elongation } \\
(\%)\end{array}$ \\
\hline $0.25-0.5$ & A710 & $80^{*}$ & $85^{*}$ & $20 \%$ in 2" * \\
\hline 0.25 & A656-80† & $81-93$ & $99-93$ & $20-24 \%$ in 2" \\
\hline 0.312 & A656-80† & 82 & 101 & $20 \%$ in 2" \\
\hline 0.375 & A572-50† & 64 & 78 & $20-21 \%$ in 8" \\
\hline 0.5 & A572-50† & $66-72$ & $78-82$ & $30-33 \%$ in 2" \\
\hline
\end{tabular}

* per specification

† per material data report

\section{FINITE ELEMENT ANALYSIS}

The three-dimensional CAD model shown in Figure 11 was used not only for fabrication of components, but also served as the starting point for building FEA models of the SOA end frame retrofit onto the end of a Budd M1 Car. Detailed finite element models of the car were constructed using the Hypermesh program. Both full-width and half-width models of the forward half of the car (i.e., half-car and quarter-car models) were built. Figure 13 shows the mesh that was constructed for the full-width model. This model uses roughly 160,000 elements, most of which are shell elements, with the remainder being beam elements. (Note that, due to the high level of mesh refinement, element outlines are not indicated in figure. The mesh is most refined near the front of the car, with a characteristic element length of approximately one inch.

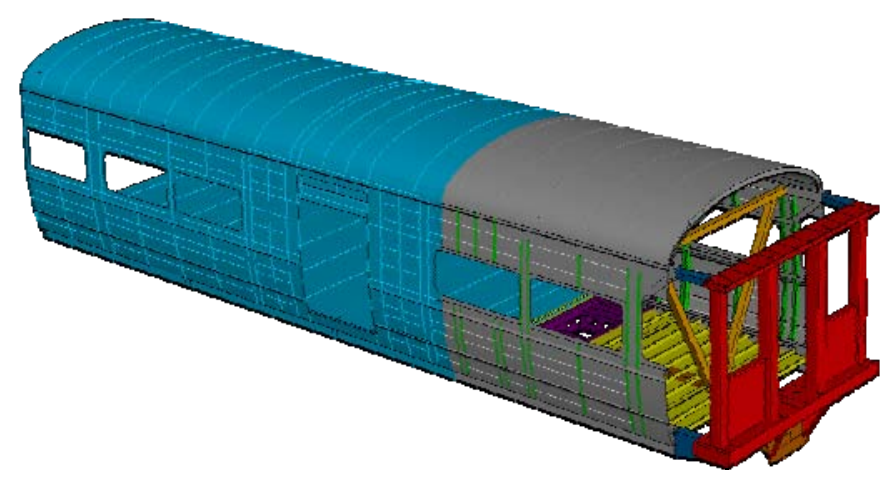

Figure 13. The finite element mesh for the full-width model of the M1 car with SOA end frame
The material models for the various steel components are based on material test report data listed in Table 1, but do not include failure.

In order to demonstrate compliance with structural requirements, a comprehensive set of analyses were performed:

- Linear and nonlinear static analyses;

- Large-deformation quasi-static analyses;

- Large-deformation dynamic impact analyses.

\section{Static Analyses}

A series of linear and nonlinear static analyses were performed to evaluate car body behavior with respect to requirements. The ten analyses that were conducted are listed in Table 2. Note that each analysis case corresponds to a section of the APTA standard. The acceptance criterion for most of the analysis cases is the absence of permanent deformation, i.e., no stresses above yield. For these cases a linear static analysis was conducted using ABAQUS/Standard. The single load case for which there is an ultimate strength requirement is the 200,000 lbf longitudinal load against the collision post, 30 inches above the underframe. For this case, a nonlinear analysis was conducted using ABAQUS/Standard.

Table 2. Static load cases

\begin{tabular}{|c|c|c|c|c|c|}
\hline $\begin{array}{l}\text { Load } \\
\text { (kips) }\end{array}$ & Orientation & Component & Location & \begin{tabular}{|c|} 
Acceptance \\
Criterion
\end{tabular} & $\begin{array}{c}\text { APTA } \\
\text { Reference* }\end{array}$ \\
\hline 800 & Longitudinal & Car Body & $\begin{array}{l}\text { Line of } \\
\text { Draft at } \\
\text { Buff Lug }\end{array}$ & Yield & 5.1.1a) \\
\hline 500 & Longitudinal & Car Body & $\begin{array}{l}\text { End Beam } \\
\text { Front Face }\end{array}$ & Yield & 5.1.1b) \\
\hline 200 & Longitudinal & $\begin{array}{c}\text { Collision } \\
\text { Post }\end{array}$ & $\begin{array}{c}\text { 30" Above } \\
\text { U/F }\end{array}$ & Ultimate & 5.3.1.3.1b) \\
\hline 60 & Longitudinal & $\begin{array}{l}\text { Collision } \\
\text { Post }\end{array}$ & $\begin{array}{c}\text { 55" Above } \\
\text { U/F† }\end{array}$ & Yield & 5.3.1.3.1c) \\
\hline 60 & Longitudinal & $\begin{array}{l}\text { Collision } \\
\text { Post }\end{array}$ & $\begin{array}{l}\text { Just Under } \\
\text { AT beam }\end{array}$ & Yield & 5.3.1.3.1c) \\
\hline 100 & Longitudinal & Corner Post & $\begin{array}{c}\text { 18" Above } \\
\text { U/F }\end{array}$ & Yield & 5.3.2.3.1b) \\
\hline 45 & Longitudinal & Corner Post & $\begin{array}{c}\text { 55" Above } \\
\text { U/F† }\end{array}$ & Yield & 5.3.2.3.1c) \\
\hline 45 & Longitudinal & Corner Post & $\begin{array}{l}\text { Just Under } \\
\text { AT Beam }\end{array}$ & Yield & 5.3.2.3.1c) \\
\hline 100 & Lateral & Corner Post & $\begin{array}{c}\text { 18" Above } \\
\text { U/F }\end{array}$ & Yield & 5.3.2.3.1b) \\
\hline 45 & Lateral & Corner Post & $\begin{array}{c}\text { 55" Above } \\
\text { U/F† }\end{array}$ & Yield & 5.3.2.3.1c) \\
\hline
\end{tabular}

A preliminary series of static analyses was conducted for an initial iteration of the design. The results of these analyses revealed two minor problem areas. For the 500,000 lbf load applied across the front of the buffer beam, a stress concentration arose at the point where the draft gear flares out 
just behind the buffer beam. Although it is likely that the magnitude of this stress is partly due to a singular nature of the connection, a stiffening plate was added. For the 60,000 lbf longitudinal load on the collision post, results indicate that when the load is applied to the post just below its connection to the AT beam, a stress exceeding yield arises in the roof connection plate due to the large moment. This noncompliance was eliminated by increasing the thickness of this plate from 0.120 inches to 0.179 inches. With these changes, the analysis results indicate that the M1 Car with SOA end frame meets all of the static load requirements.

\section{Quasi-static Analyses}

Quasi-static analyses were performed using ABAQUS/Explicit. The mesh for the collision post load case is shown in Figure 14. The load is applied via a rigid loading device that is 10 inches high and is as wide as the post (6.5 inches). (For the corner post load case, the load plate is moved to the corresponding location on that post.) A graduallyincreasing displacement was imposed on the rigid loading device, with a final extension of 10 inches.

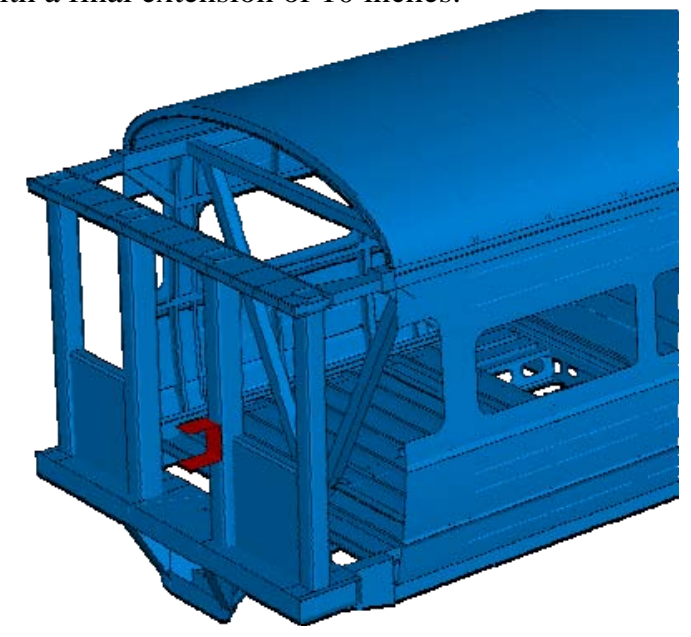

Figure 14. The finite element mesh for the quasi-static collision post load case

The deformation of the end frame that arises when the collision post is displaced by 10 inches is shown in Figure 15. Plastic deformation is generally confined to the collision post, the shelf and bulkhead, the AT beam in the vicinity of the collision, and the corner post adjacent to the shelf connection. There is a also a little bit of deformation in the side sill and roof rail connection plates on the loaded side of the car, but essentially no deformation in the reinforced car body, behind the connections to the end frame, as desired. Contours of equivalent plastic strain shown in Figure 15 indicate that high levels of tensile strain arise at the front base of the collision post, and at back of the post opposite the point of load application. At the base of the post, the equivalent plastic strain reaches about $37 \%$. At the back of the post, opposite the load application point, the equivalent plastic strain reaches $22 \%$.

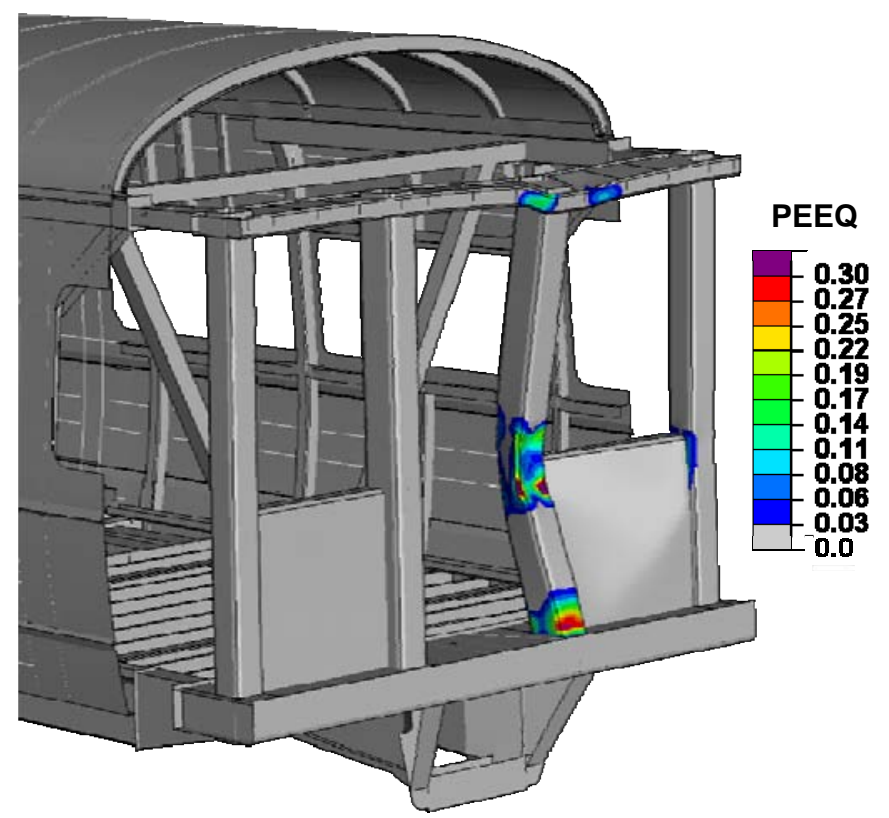

Figure 15. Contours of equivalent plastic strain for the quasi-static collision post load case

Similar results are predicted for the corner post quasistatic load case. The predicted deformation at 10 inches of load point displacement is shown in Figure 16. For this case, the deformation is localized to the corner post, the shelf where it connects to the collision and corner posts, the bulkhead plate, the AT beam where it connects to the corner post, and both the side sill and roof rail connection members. The equivalent plastic strain at the front bottom of the corner post reaches $19 \%$, while the back of the post opposite the load point reaches a strain of about $28 \%$.

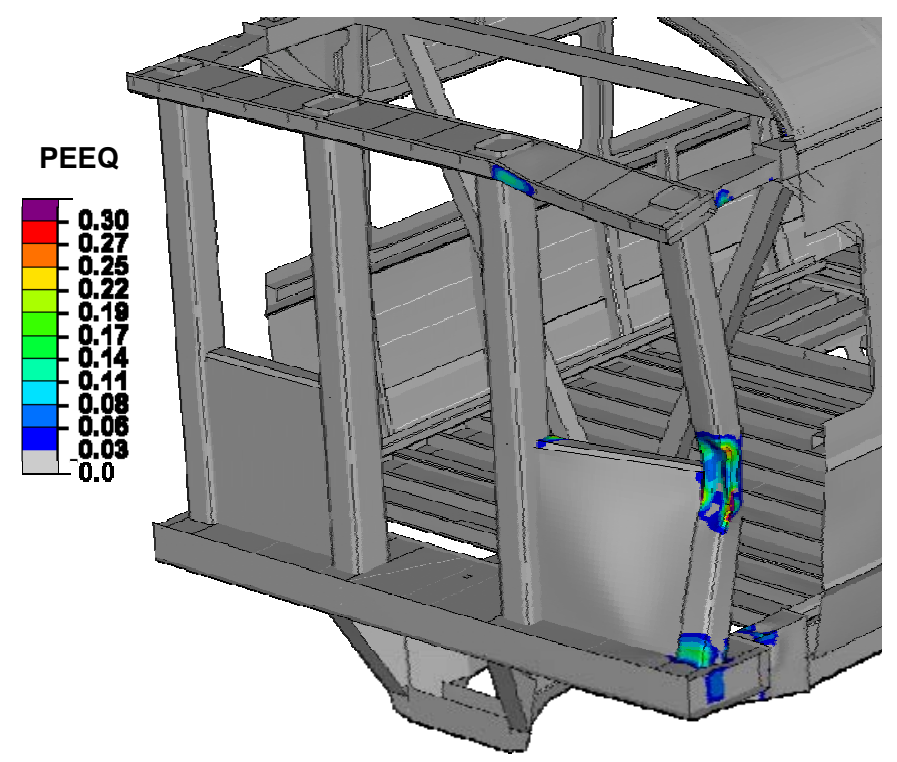

Figure 16. Contours of equivalent plastic strain for the quasi-static corner post load case 


\section{Dynamic Coil Impact Analyses}

A similar set of analyses were run to simulate dynamic impact test conditions. The mesh for the collision post coil impact case is shown in Figure 17. For the dynamic analyses, the coil was assigned a mass of $10,000 \mathrm{lbm}$ and an initial velocity equal to $21 \mathrm{mph}$ for the collision post impact and 20 mph for the corner post impact.

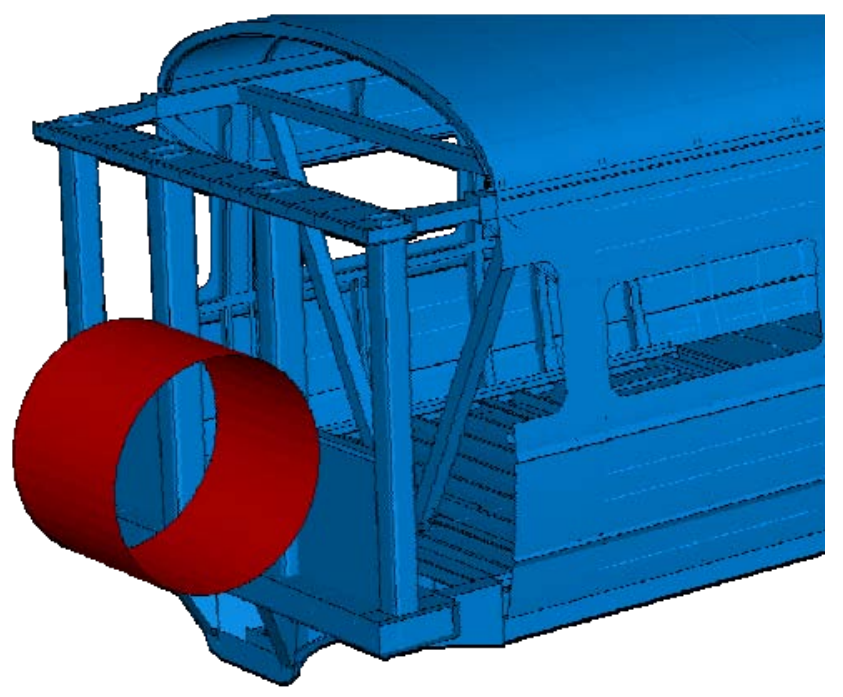

Figure 17. The finite element mesh for the dynamic coil impact of the collision post load case

The deformation modes for these analyses are very similar to those depicted in Figures 15 and 16 for the quasistatic cases. For the collision post case, the coil deflects by 7.4" into the post before rebounding off. The back of the collision post intrudes into the occupied volume by 6.4". (The difference between these two values is due to local crushing of the post.) Equivalent plastic strains of $29 \%$ and $16 \%$ arise at the front base of the post and the back of the post opposite the point of impact, respectively. These values are smaller than those predicted by the quasi-static load case at a deformation of 10 inches, but are quite consistent with quasi-static predictions at corresponding levels of displacement.

For the corner post impact case, the coil deflects by 8.3" and the post intrudes into the occupant volume by 8.0 ". The larger displacement relative to the collision post case is due to the much smaller size of the post, which more than offsets the effect of using a stronger material (A656-80) in the corner post than is used in the collision post (A572-50).

A comparison of the load-displacement curves for all four quasi-static and dynamic load cases is shown in Figure 18. As expected, the corresponding curves are similar. For the quasi-static collision post load case, when the deformation energy reaches 135,000 ft-lbs, the post has intruded 6.4" into the occupied volume, essentially the same as for the dynamic case. For the quasi-static corner post load case, when the deformation energy reaches $120,000 \mathrm{ft}-\mathrm{lbs}$, the post has intruded over 7.8" into the occupied volume, versus 8.0 " for the dynamic case.

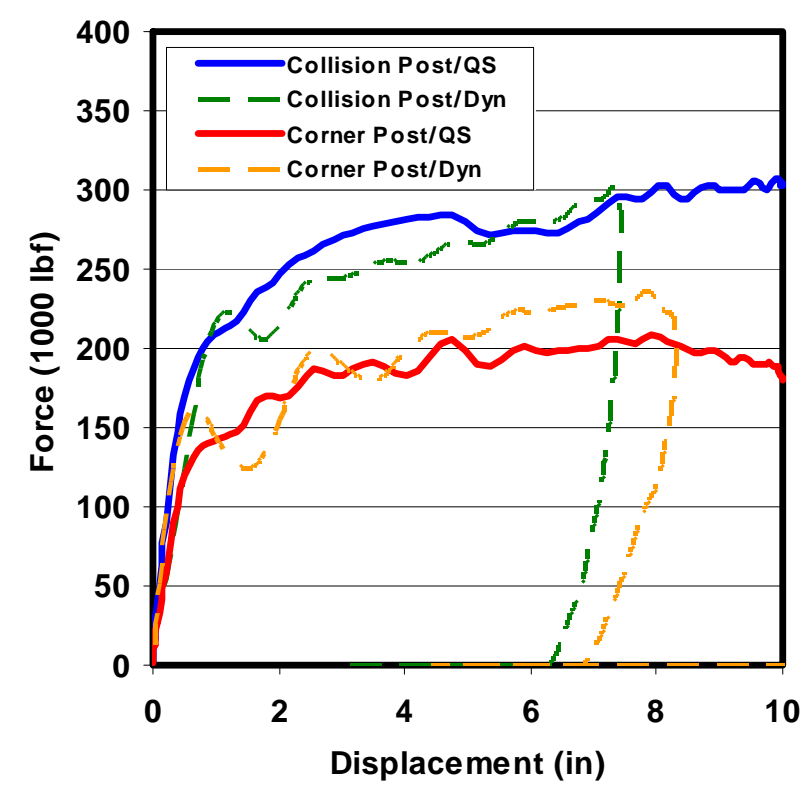

Figure 18. Comparison of force-displacement results for the four quasi-static and dynamic coil impact cases

\section{Pre-test Simulation of Collision Post Coil Impact}

Prior to the dynamic test, a third coil impact analysis was performed, replacing the $10,000 \mathrm{lbm}$ rigid coil with a 14,180 lbm rigid cart that was used to impact the collision post [5]. The finite element model used for this analysis is shown in Figure 19, and includes a forward truck. In addition, the back of the mesh was not constrained, but instead, the mass of the complete cab car was distributed into the back of the car, so that it moved backward at an appropriate speed on impact. The analysis was performed for a collision speed of $20 \mathrm{mph}-$ the high end of the expected range for the test.

The results of the simulation are very similar to the previous quasi-static and dynamic collision post load case simulations. The final displacement of the post is predicted to be 6.5 inches.

The test was successful, with a measured final displacement of about 7.5 inches for a slower collision speed of $18.7 \mathrm{mph}$. The difference is attributable to fracture that occurred at the front base of the post and at the back of the post opposite the point of impact, as illustrated in Figure 20. The post remained attached, as required. While these were predicted to be the highest tensile strain regions (see Figure 15), the model did not include material failure, and thus was not able to capture the fracture. Aside from the fracture, the model was generally able to capture the deformation modes that were observed in the test, including the puckering-in of the front face of collision post around the point of impact, the folding of the shelf, and the bending down of the AT plate near its connection to the collision post. Consistent with model predictions, no permanent deformation of the M1 car body was observed following the test, which was a key design requirement. 


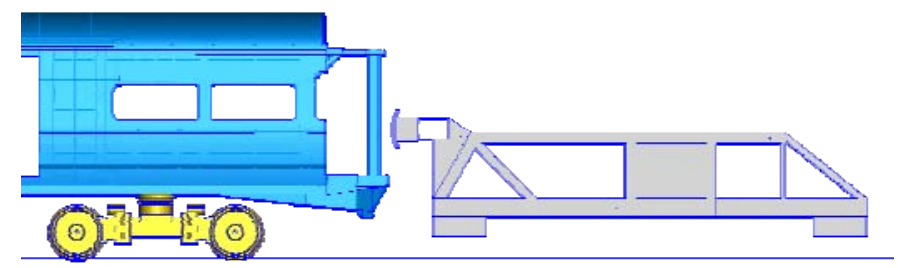

Figure 19. Finite element model for simulation of cart impact into collision post (back end of cab car not pictured)

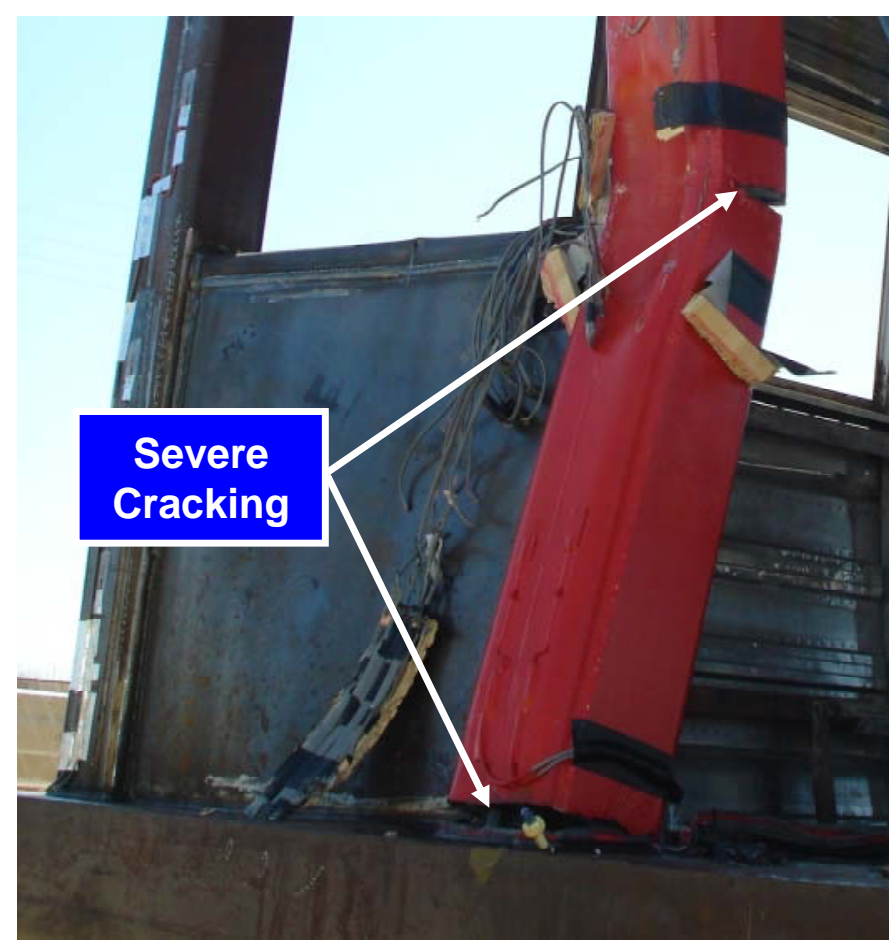

Figure 20. In the dynamic coil impact test, fracture occurred at the front base of the post and at the back of the post, opposite the point of impact

\section{DISCUSSION AND CONCLUSIONS}

One of the primary objectives of the research program described here was to design and oversee the construction of a retrofit of the SOA end frame onto an M1 car so that it could be used for quasi-static and dynamic testing. The successful dynamic test conducted in April 2008 demonstrates that this objective was clearly met - the test was a success and the M1 car body was not damaged, enabling it to be re-used for subsequent tests.

The second objective of this research was to assess whether the two test methods offer equivalent means of evaluating the energy absorption characteristics of the cab car end structure. It is too early to assess whether this objective has been met. The results of the FEA models clearly indicate that the two methods result in similar modes of deformation and similar measures of energy absorption. However, as noted, the models described above do not include material failure. It has been recognized from the start of this program that fracture would likely occur during the tests. There was fracture during the corner post coil impact test, and a similar extent of fracture was expected during the collision post impact test.

The fracture that occurred during the dynamic collision post test was more extensive than expected, and likely revealed a flaw in the design of the end frame where the shelf connects to the collision and corner posts. Certain aspects of this connection have since been modified.

Recognizing the importance of fracture for making an assessment regarding the equivalence of the two alternative test methods, this research program was recently expanded to evaluate analytically the effect of fracture on the behavior of the end frame during the quasi-static and dynamic loading scenarios described here. Material failure models that account for the influence of stress state on the propensity for fracture [6] have been incorporated into the ABAQUS model. These material failure models have recently been shown to provide excellent agreement to the results from a series of tank car dynamic impact/puncture tests [7]. In addition, material tests are being planned so that the failure models can be calibrated.

\section{ACKNOWLEDGMENTS}

This work was performed under contract to the Volpe Center as part of the Equipment Safety Research Program sponsored by the Office of Research and Development of the Federal Railroad Administration. The authors sincerely appreciate the support and guidance offered by Michelle Priante, technical representative for this program, as well as David Tyrell, Patricia Llana, and Benjamin Perlman of the Volpe Center. The authors also with to thank Eloy Martinez and Luis Maal of the Federal Railroad Administration, Mark White and Tom Roderick of TTCI, and Ed Dunn of Zimmerman Metals, Inc.

\section{REFERENCES}

1. Notice of Proposed Rulemaking, "Passenger Equipment Safety Standards; Front-End Strength of Cab Cars and Multiple-Unit Locomotives, “49 CFR Part 238, Federal Register, Volume 72, No. 147, August 1, 2007, pp 42016-42041.

2. APTA SS-C\&S-034-99, Rev. 2, "Standard for the Design and Construction of Passenger Railroad Rolling Stock", Vol. II-Construction and Structural, pp 11.0-11.44, American Public Transportation Association, 2003.

3. Mayville, R., Stringfellow, R., Martinez, E., "Development of Conventional Passenger Cab Car End Structure Designs for Full-Scale Testing, "U.S. Department of Transportation, DOT/FRA/ORD-06/20, December 2006.

4. Martinez, E., Tyrell, D., and Zolock, J., "Rail-Car Impact Tests with Steel Coil: Car Crush,” Proceedings of 
ASME/IEEE Joint Railroad Conference, Paper No. JRC2003-1656, April 2003.

5. Priante, M., Llana, P., Jacobsen, K., Tyrell, D., and Perlman, B., "A Dynamic Test of a Collision Post of a State-of-the-art End Frame Design," American Society of Mechanical Engineers, Paper No. RTDF2008-74020, September 2008.

6. Bao, Y. and Wierzbicki, T, "On Fracture Locus in the Equivalent Strain and Stress Triaxiality Space," International Journal of Mechanical Sciences, 46, 81-98, 2004.

7. Tang, Y, Yu, H, Gordon, J, Priante, M, Jeong, D, Tyree, D, Perlman, A, "Analysis of Full-Scale Tank Car Shell Impact Tests," Proceedings of 2007 ASME Rail Transportation Division Fall Technical Conference, RTDF2007-46010, 2007. 